\title{
Normas PenAles y CONFlicto De Deberes
}

\author{
RESPUESTA A LAS CRÍTICAS
}

Juan Pablo Alonso ${ }^{1}$

$\overline{{ }^{1} \text { Universidad de Buenos Aires. }}$

\section{Luís Duarte D'Almeida.}

Las críticas de d'Almeida hacia mi trabajo se centran en una supuesta errónea reconstrucción del pensamiento kelseniano. Puntualmente, respecto de mi noción de "deber jurídico por derivación kelseniana" que d'Almeida considera insostenible; de este error se sigue, según d'Almeida, que el problema planteado en "Normas Penales y Conflicto de Deberes" se disuelve $a b$ initio como un falso problema.

De su análisis, d'Almeida concluye que es un error "entender que el contenido de un deber derivado es coincidente con el contenido del antecedente de la norma de sanción a partir de la cual se deriva el deber". 
Señala que los dos deberes que se analizan como en conflicto (el deber de no pagar por fuera de las reglas concursales y el deber de pagar el cheque rechazado) no son derivables en los términos en que se pretende en "Normas Penales y Conflicto de Deberes", por lo que las afirmaciones de que "existe un conflicto entre deberes jurídico-penales" y que "el sistema secundario sujeta al agente a dos deberes jurídicos que no puede satisfacer simultáneamente" están fuera de lugar.

Antes de ingresar en detalle en las críticas de d'Almeida, quiero señalar que los otros tres críticos (Ortiz de Urbina, Verde y Peralta) no han dudado en suscribir mi tesis de que existe un genuino conflicto de deberes jurídico-penales entre el deber de no pagar por fuera de las reglas del concurso y el deber de pagar el cheque rechazado (si bien Ortiz de Urbina es oscilante en este punto), aunque disienten conmigo en la forma en que resuelvo tal conflicto. En su crítica de que nos encontramos frente a un falso problema, d'Almeida se encuentra en soledad.

\subsection{Sanción en sentido amplio y sanción stricto sensu.}

Señala d'Almeida que en "Normas Penales y Conflicto de Deberes" no se recoge la distinción kelseniana entre "sanción en sentido amplio" y "sanción stricto sensu". Las primeras se refieren a "todos los actos coactivos estatuidos por el orden jurídico", mientras que en las segundas (stricto sensu) la idea de sanción es equivalente a la de "pena" que tiene que aplicarse como consecuencia de una conducta. "Es claro -señala d'Almeida- que para Kelsen las normas de conducta cuya "derivación" está aquí en juego deben ser derivadas no de las normas sancionatorias en sentido amplio, sino de las normas sancionatorias stricto sensu.

Señalo, de manera preliminar, que, con independencia de que la distinción entre sanción en sentido amplio y sanción stricto sensu sea una razonable exégesis de la obra de Kelsen, lo cierto es que tal distinción es irrelevante para el objetivo desarrollado en "Normas Penales y Conflicto de Deberes". Si, como señala d Almeida, la tesis de 
la derivación sólo se aplicaría para los casos de sanción stricto sensu (por ejemplo, a las sanciones penales) entonces tal tesis estaría correctamente aplicada en "Normas Penales y Conflicto de Deberes" ya que se trata del conflicto emergente entre dos normas del derecho penal argentino que imponen sanciones penales; complementariamente, de prisión y multa. Por tanto, tal distinción propuesta carece de impacto en el trabajo que se pretende criticar.

\subsection{El problema de la norma penal "completa".}

d'Almeida sostiene que en mi trabajo existe una confusión en cuanto a mi reconstrucción kelseniana sobre la prelación existente entre "deber" y "sanción”. Con justicia d'Almeida señala que no estoy sólo en esa confusión, ya que Hart también había sostenido una tal exégesis de Kelsen.

d'Almeida sostiene que, en términos conceptuales, la idea de deber es previa a la idea de sanción, y por tanto sería errónea la caracterización de "secundaria" de la norma de deber y la de "primaria" de la de sanción; tales términos, señala d'Almeida, deberían invertirse.

Para ello, d'Almeida acude a una exégesis del pensamiento de Kelsen en donde se concluiría que para Kelsen la idea de deber es previa a la de sanción. Según Kelsen, el antecedente de la sanción se configura por una norma extremadamente compleja que incluye múltiples condiciones diferentes que son extraídas de expresiones legislativas dispersas por todo el ordenamiento jurídico. De ahí concluye que la sanción requiere de la infracción de algún deber, pero cuál es ese deber depende de construir criterios que nos permitan discernir, de entre todos los requisitos de la sanción, cuál debe elegirse como "el deber jurídico relevante". Señala d'Almeida, adecuadamente, que los criterios elaborados por Kelsen para solventar esta problemática no han tenido éxito. Sin embargo, señala d'Almeida que tampoco han tenido éxito las teorías dogmáticas penales que no llegan a ponerse de acuerdo sobre cuáles son las condiciones de la norma de conducta, ya que se distingue entre justificaciones y excusas como elementos que excluyen la responsabilidad penal, incluyendo a las primeras (pero no a las 
segundas) como delimitando el campo de la antijuridicidad. Por otro lado quedan afuera del concepto de delito las cuestiones sobre la perseguibilidad penal o la competencia de los jueces, aunque cada uno de estos elementos, fuera de la noción de delito, también serían, en algún sentido, condición de la sanción penal.

\subsection{Los dos errores de "Normas Penales y Conflicto de Deberes" según d'Almeida.}

Así las cosas, en el trabajo "Normas Penales y Conflicto de Deberes" se habría incurrido en dos errores:

En primer lugar, se intenta derivar "deberes jurídicos" de normas incompletas, esto es, de normas que no han sido completamente articuladas en cuanto a las condiciones para la sanción penal. Las normas derivadas en el trabajo indican sólo una de las condiciones de la sanción: la condición que en la dogmática penal suele recibir el nombre de "tipo objetivo".

El segundo error sería consecuencia del primero; en el trabajo se afirma que existe un conflicto de deberes jurídicos cuando, a lo sumo, hay un conflicto entre tipos penales, existiendo duda sobre si el agente debe o no debe pagar el cheque. La respuesta a esta duda dependerá de las condiciones bajo las cuales el juez debe imponer una sanción penal al incumplidor del deber.

Para d'Almeida es incorrecto presuponer que sea un problema de "conflicto" entre "deberes jurídico-penales", o que "el sistema secundario sujeta al agente a dos deberes jurídicos que no puede satisfacer simultáneamente". Según d'Almeida lo único que puede afirmarse sin más es que cualquiera de los comportamientos realiza, prima facie, un tipo penal, toda vez que los casos (1) y (2) del sistema primario incluyen solamente la descripción de los comportamientos típicos de cada infracción y la realización de un tipo penal no es condición suficiente para la imposición de una sanción. 


\subsection{El supuesto avance de mi propuesta por encima de los límites teóricos y dogmáticos.}

En el punto 1.1. ya he explicado porqué entiendo que la distinción entre sanción en sentido amplio y sanción stricto sensu (sanción penal) es irrelevante en este entorno, ya que el problema que analizo en "Normas Penales y Conflicto de Deberes" es un problema de índole penal, por lo que no existirían mayores reparos para aplicar la regla de conversión, si el único obstáculo fuese que sólo se aplica a conductas correlacionadas con sanciones stricto sensu.

Pero está claro que para d'Almeida ese no es el único obstáculo.

El obstáculo central sería, a entender de d'Almeida, que ni la teoría del derecho ni la dogmática penal han avanzado lo suficiente como para determinar criterios claros para establecer cuál es el deber jurídico penal y así distinguirlo de entre las numerosas condiciones que se requieren para la procedencia de una sanción penal.

Yo no creo que éste sea un obstáculo para intentar aplicar un modelo teórico como el de Kelsen en el análisis de un problema penal.

En su Teoría Pura del Derecho Kelsen especificó "la regla de conversión" para pasar de una norma sancionatoria a una norma de deber. Que su empresa haya quedado incompleta no nos permite afirmar que haya sido una empresa inútil.

Los dogmáticos penales tampoco han resuelto del todo problemas análogos y no por ello creen que deben quedarse de brazos cruzados frente al análisis de problemas normativos.

Creo que ese es el punto.

Por la regla de conversión Kelseniana se ha podido reconstruir el sistema normativo del Juez y el sistema normativo del ciudadano; se ha podido, además, determinar las relaciones entre ambos sistemas normativos. Hemos detectado un conflicto en el sistema del ciudadano que no presenta analogía en el sistema del Juez y nos hemos preguntado si el Juez debe atender o hacer caso omiso al conflicto en cuestión.

d'Almeida nos dice que es un falso conflicto, ya que no han sido (porque no pueden ser) especificadas todas las condiciones de la sanción. Pero en todo caso d'Almeida debería haber demostrado cuál de 
las condiciones no analizadas resulta crucial para subvertir, diluir o anular el conflicto planteado. Pero como d'Almeida no lo hace (ni siquiera lo intenta) entonces su crítica queda sólo en una petición de principios, señalando que se ha avanzado en un caso concreto más de lo que la teoría y la dogmática lo han hecho.

Como dije en la presentación de las críticas de d'Almeida, los otros tres críticos no han dudado en señalar que nos encontramos frente a un genuino conflicto de deberes, y ello más allá de que la teoría y la dogmática no han resuelto todos los problemas que tal caracterización supone. Al respecto cito a Ortiz de Urbina, que señala,

\begin{abstract}
en el caso que nos ocupa, el problema jurídico penal descrito por Alonso es fácilmente identificable como un supuesto de colisión de deberes"; y a Verde, que sostiene "si bien cabe coincidir con Alonso en que, prima facie, se está frente a un conflicto de deberes jurídicos, ha de rechazarse la solución a la que él arriba.
\end{abstract}

\title{
2. Í̃̃igo Ortiz de Urbina Gimeno.
}

Las críticas de Ortiz de Urbina comienzan señalando sobre la utilización trivial (o innecesaria) que se efectúa de las herramientas metodológicas del análisis lógico del derecho. Señala que se identifica un problema utilizando un engorroso material para luego resolverlo con arreglo a la dogmática penal clásica y sin conexión con el engorroso material inicialmente usado. Analiza las relaciones entre el sistema del juez y del ciudadano, afirmando lo trivial que resulta mi comparación entre el sistema del juez y el sistema del ciudadano cuando éste último es incompleto, dado que en el derecho penal no hay lagunas normativas.

Continúa señalando sobre la inadecuada especificación que se realiza de los sistemas del juez y del ciudadano, ya que sólo incluye normas sobre la tipicidad y se excluyen, deliberadamente, normas que establecen eximentes.

Finaliza su análisis criticando mi propuesta de que bajo cualquier condición el sujeto debería ser absuelto. Para Ortiz de Urbina, 
dada la mayor pena atribuida al delito de quiebra, el agente deberá omitir pagar el cheque para satisfacer el deber emergente del art. 176 inc. $3^{\circ} \mathrm{del}$ cód. penal. En caso de que pague el cheque deberá ser sancionado por violar la pars conditio creditorum, salvo que se pruebe la existencia de un error invencible.

Anticipo que las críticas de Ortiz de Urbina me dejan ciertas perplejidades. La primera es que inicialmente afirma que es un genuino conflicto de deberes ("el caso es fácilmente identificable como un supuesto de colisión de deberes" dice en sus primeras páginas), luego afirma que esa colisión de deberes ha sido construida artificialmente por manipulación de los axiomas de los sistemas normativos y la omisión de normas relevantes, y por último afirma que el conflicto (que finalmente acepta como un genuino conflicto) se resuelve cumpliendo el deber de mayor jerarquía (esa es su conclusión). La segunda perplejidad es sobre la supuesta innecesariedad del método analítico para elucidar cuestiones de dogmática penal, aunque luego propone integrar normas de la parte general a los sistemas del juez y del ciudadano de un modo confuso pero que, según él, nos permitiría un análisis más fructífero.

\subsection{La supuesta inadecuada caracterización de los sistemas normativos del juez y del ciudadano.}

Recordemos que en mi esquema construyo inicialmente la matriz del sistema normativo del juez y del ciudadano sobre la base de los tipos penales de los arts. 176 inc. 3 (quiebra fraudulenta) y 302 inc. 1 (libramiento de cheque sin provisión de fondos). Detecto un conflicto de deberes en el sistema del ciudadano y me pregunto si tal conflicto tiene relevancia en el sistema del Juez, más allá de que éste no lo recoja. Sentada la cuestión, continúo el análisis comparando las diversas soluciones posibles al conflicto, analizando entre otras cuestiones, los diversos eximentes aplicables al caso, como ser el estado de necesidad y el cumplimiento de un deber (art. 34 incs. $3^{\circ}$ y $4^{\circ}$ del cód. penal).

La crítica de Ortiz de Urbina se dirige a señalar que nunca debí analizar los eximentes a posteriori sino que debí analizarlos inicialmente, 
de manera contemporánea a la construcción de la matriz de ambos sistemas (el del juez y el del ciudadano).

Creo que esto es un error, y el mismo parte de no comprender el distinto funcionamiento normativo-analítico de las normas penales de la parte especial y de las normas penales de la parte general.

Las normas de la parte especial tienen la estructura del tipo kelseniana "si cometes $\mathrm{p}$ entonces es obligatorio la sanción q". Las normas de la parte general tienen un funcionamiento lógico muy diferente; carecen de la estructura kelseniana y, en general, tienen un carácter metanormativo, ya que son normas que se refieren a otras normas; estas segundas normas ("normas objeto") pueden ser tanto normas de la parte especial como de la parte general ${ }^{2}$.

Uno de los axiomas metodológicos de la construcción de sistemas normativos es que debe existir un Universo del Discurso que aglutine la selección de normas a analizar y que el Universo de Soluciones esté dado por los mismos contenidos normativos ${ }^{3}$.

No es que no puedan construirse sistemas normativos con normas de la parte general ${ }^{4}$, pero lo que definitivamente no puede hacerse es mezclarse de manera indiscriminada normas que poseen estructuras y funcionalidades distintas y que responden a niveles normativos distintos. El análisis en etapas o niveles es una de las características centrales del análisis lógico del derecho.

Una cosa es que un modelo, para ser plausible, deba poder analizar todos los aspectos relevantes de un fenómeno normativo. Otra cosa, muy distinta, es que todo deba analizarse al mismo momento, en el mismo nivel y con las mismas herramientas metodológicas. Ello parece exigir Ortiz de Urbina del modelo lógico analítico del derecho.

\footnotetext{
${ }^{2}$ Por ejemplo, el criterio de la ley penal más benigna es metanormativo respecto de (se aplica a) normas de la parte especial (un tipo que luego tiene una pena más leve), como a normas de la parte general (mejores condiciones para la prescripción de la acción penal). Ver Alonso Juan Pablo, Interpretación de las normas y derecho penal, págs. 142 y ss. (Editores del Puerto. Buenos Aires, 2006).

${ }^{3}$ Carlos Alchourrón y Eugenio Bulygin 1971, Normative Systems, pág. 32 y ss. (Editorial Astrea. Buenos Aires, 1974, traducción de los autores.)

${ }^{4}$ En Interpretación de las normas y derecho penal (op. cit.) construyo la matriz del sistema de suspensión del juicio a prueba del derecho argentino (art. 76 bis del código penal argentino) (págs. 9 y ss.).
} 
En efecto, en "Tiempo y validez"5, Bulygin nos explica, con la precisión analítica que lo caracteriza, el funcionamiento metanormativo de los criterios de aplicabilidad de la ley en general, y de la ley penal en especial. No recurre a la construcción de una matriz (cosa que hubiera hecho si era pertinente, ya que él, junto con Carlos Alchourrón, son los inventores de la "matriz de los sistemas normativos"), por la simple razón de que considera que ese método de reconstrucción racional no es el adecuado para el fenómeno de la metanormatividad.

También en El Concepto de sistema jurídico ${ }^{6}$ Raz nos explica las diversas relaciones internas y externas existentes entre las distintas disposiciones de los sistemas jurídicos, señalando que una misma disposición interactúa de diversas formas metodológicas conforme sean distintas las funcionalidades de las otras disposiciones con las que se relaciona.

No creo necesario ahondar más en posiciones metodológicas que respaldan mi decisión de efectuar un análisis en etapas y con metodologías distintas. Lo cierto es que considero infundado el reclamo de Ortiz de Urbina de que las matrices del sistema del ciudadano y del juez están mal construidas. Está claro que Ortiz de Urbina no es un experto en el análisis lógico del derecho ni en Normative Systems; ni tampoco tiene porqué serlo ya que sus intereses pasan por la dogmática penal. Por eso resulta curioso que se expida tan categóricamente sobre un terreno que, claro está, desconoce absolutamente.

En "Normas Penales y Conflicto de Deberes" lo que se efectúa es un análisis en etapas, y la conclusión a que se arriba respecto de que hay un conflicto de deberes lo es sólo prima facie, aclarando que restan niveles por analizar. No entiendo porqué la insatisfacción de Ortiz de Urbina sobre este punto, máxime si en la disciplina en la que es experto, la teoría del delito, el análisis estratificado de los problemas es un rasgo metodológico importante.

\footnotetext{
${ }^{5}$ Eugenio Bulygin, "Tiempo y validez" en Análisis Lógico y Derecho, págs. 195 y ss. Centro de Estudios Constitucionales. Madrid 1991.

${ }^{6}$ Joseph Raz, El concepto de sistema jurídico. Universidad Nacional Autónoma de México. México, 1986 (traducción de Tamayo Salmorán).
} 


\subsection{La supuesta resolución del conflicto.}

En "Normas Penales y Conflicto de Deberes" sostengo que no puede establecerse una primacía clara entre los dos deberes en conflicto, y como consecuencia de ello, afirmo que el juez deberá absolver en cualquier supuesto.

Ortiz de Urbina afirma lo contrario; sostiene que el tipo de quiebra fraudulenta (176 inc. 3) establece un deber superior al tipo de cheque sin fondos (302 inc.1), por lo que en caso de conflicto el sujeto quedará exento de responsabilidad cumpliendo con ese deber.

Ortiz de Urbina no analiza la eximente de "cumplimiento de un deber" contenido en el inc. 4 del art. 34 del código penal argentino. Su análisis del conflicto de deberes lo efectúa como una instancia del estado de necesidad.

Descartando el argumento cualitativo en cuanto a la posible inconmensurabilidad de los bienes jurídicos tutelados, Ortiz de Urbina se decanta por el argumento cuantitativo: como la pena para el delito de quiebra es mayor que la pena del delito de cheque, entonces el deber emergente del primero es superior al deber emergente del segundo.

Sin embargo, Ortiz de Urbina omite analizar una parte del tipo penal de quiebra que señala que la prohibición es de "conceder ventajas "indebidas" a cualquier acreedor". Ahora bien, si se acepta que existe el deber de pagar el cheque, deber que subsiste en aquellos casos en que el deudor no está sujeto a un proceso de quiebra, ¿porqué tal deber de pagar el cheque no existe cuando el deudor esta en proceso de quiebra? ¿Ya no es un deber "debido" sólo por la particular situación del deudor? ¿Deja de ser un "deber debido" porque el otro tipo penal impone una pena más grave? ¿Porqué no sostener que están prohibidos los pagos "indebidos" pero como en este caso el pago es "debido" en función de otra norma penal entonces el acreedor debe pagar el cheque y ese pago le excepciona de la pena del delito de quiebra?

Ortiz de Urbina no da respuesta a estas cuestiones; su afán de presentar el problema como un problema fácilmente resoluble (o un falso problema) le impide ingresar en estas cuestiones de detalle que podrían inclinar la balanza hacia un lado u otro. 


\section{Alejandra Verde.}

Las críticas de Verde hacia mi trabajo se centran en la segunda parte del mismo, esto es, en mis análisis sobre cuál es la posición del juez frente al conflicto de deberes detectado entre los dos tipos penales analizados.

En tal sentido, Verde parece aceptar como correcta mi caracterización de las normas primarias y secundarias, como también la forma en que se caracterizan e interrelacionan el sistema del juez y el sistema del ciudadano. Por omisión, parece entender que las críticas de d'Almeida y Ortiz de Urbina a la utilización del modelo analítico para dar cuenta del conflicto son improcedentes. Ello porque, de hecho, su punto de partida para efectuar sus críticas se apoya en la caracterización analítica que se efectuó de los sistemas primarios y secundarios y, en especial, en el conflicto de deberes jurídico-penales detectado. Al respecto afirma, "si bien cabe coincidir con Alonso en que, prima facie, se está frente a un conflicto de deberes jurídicos, ha de rechazarse la solución a la que él arriba".

\subsection{El cumplimiento de un deber como causa de justificación. La supuesta prevalencia de los deberes de omisión por sobre los deberes de acción.}

Verde comienza señalando que según mi posición, pague o no pague el agente no podrá ser objeto de sanción penal por ausencia de antijuridicidad. Señala que mi posición es criticable ya que no especifico cuál es la causa de justificación aplicable.

En esto Verde se equivoca. En efecto, en el punto 5.1. de mi trabajo ("la condena bajo cualquier supuesto") comienzo analizando la posible atipicidad por indominabilidad de la conducta, para luego dar lugar al siguiente análisis:

Un conflicto de deberes jurídicos puede llevar a un agente a cumplir un deber en desmedro de otro porque considera, con o sin razón, que uno de los deberes prevalece sobre el otro. Si 
el agente eligió cumplir con el deber jurídicamente superior, su accionar típico se encontrará justificado ${ }^{20}$.

La nota al pié (que aquí reproduzco) dice: " ${ }^{20}$ El cumplimiento de un deber es una causa de justificación expresamente prevista por el art. 34 inc. 4 del cód. penal argentino".

La posibilidad de que un deber sea superior a otro lleva a que yo concluya en que no puede sostenerse la condena bajo cualquier supuesto. Asimismo, en el punto siguiente (5.2.) efectúo una ponderación entre los dos deberes jurídicos en juego, teniendo en cuenta la pena, el bien jurídico tutelado y el modo de agresión al mismo, concluyendo que no puede afirmarse que un deber es superior a otro.

Por tanto, las afirmaciones de Verde relativas a que mi trabajo se apoyaría en alguna "causa de justificación supralegal", son injustificadas. En todo momento analizo la posible solución al caso a la luz de la causa de justificación "cumplimiento de un deber" contenida en el art. 34 inc. 4 del código penal argentino.

Posteriormente, desmenuzando la obra de Roxin, Verde analiza la colisión entre un deber de acción y un deber de omisión, en el caso, el deber de pagar y el de no pagar. No coincido, nuevamente, con Verde, en que la solución a esta colisión estaría amparada bajo una causa de justificación supralegal ya que, a mi entender, el conflicto se sigue manteniendo en el ámbito normativo del inc. 4 del art. 34, que considera al cumplimiento de un deber como causa de justificación autónoma. La cuestión, a mi entender, es determinar si alguno de esos deberes es superior al otro, con independencia de si un deber es de acción y el otro de omisión.

Continuando su análisis, y de manera preliminar, Verde coincide con Roxin en lo siguiente:

si se da una colisión entre dos (o más) deberes de acción de igual o similar jerarquía y referidos a un mismo bien jurídico, debe considerarse lícita (esto es, no antijurídica) la conducta del sujeto cualquiera sea el deber que cumpla.

En esto coincido plenamente, pero no en su análisis inmediato siguiente. 
En efecto, Verde me critica porque dice que yo aplico esta doctrina alemana (basada en causas de justificación supralegales) a deberes de acción y de omisión, pero tal doctrina alemana no aceptaría mi aplicación.

Señala Verde que en esta doctrina alemana, cuando colisionan dos deberes de igual o similar jerarquía, pero uno es de acción y el otro es de omisión, prevalece el de omisión. Afirma Verde que, del mismo modo en que entre matar y no matar prevalece no matar, entre pagar y no pagar prevalece no pagar.

No estoy de acuerdo con esta conclusión de Verde, que se asemeja mucho a una mera petición de principios. Primero, porque mi punto de partida es una causa de justificación positiva, contenida en el art. 34 inc. 4 del código penal y no en una causal supralegal. Segundo, porque entiendo que no existe ningún paralelismo entre "matar/no matar" y "pagar/no pagar". En ciertos contextos matar estará justificado pero siempre será preferible no matar a hacerlo. La acción de pagar, en cambio, es absolutamente neutral y hacerlo u omitirlo dependerá de cuál es el deber jurídico superior, y si no existe tal deber jurídico superior, el agente podrá hacer cualquiera de las dos acciones, y en ninguna de las dos hipótesis puede ser sancionado. Ninguno de los argumentos dogmáticos de Verde permite dar prevalencia, per se y bajo igualdad de circunstancias, a la acción de omitir pagar por sobre la de hacerlo.

\subsection{La ponderación entre los dos deberes jurídicos en pugna.}

En este punto, Verde comienza explicando, a través de varios ejemplos, cómo en muchas ocasiones un deber jurídico prevalece sobre otro, sea por razones de jerarquía, sea por razones de especificidad.

Analizando el caso concreto, Verde refiere que una vez que el sujeto es declarado en quiebra tiene el deber específico de no pagar el cheque rechazado, por su específica situación de quebrado. El nacimiento de ese deber específico hace que el deber general de pagar el cheque rechazado ceda. 
Además, señala Verde, que el delito de quiebra protege la propiedad privada y el delito de cheque protege la fe pública, afirmando que el primer bien jurídico, por ser individual, es jerárquicamente superior al segundo, que es colectivo. Siguiendo a Alexy, Verde afirma que existe una preferencia general prima facie a favor de los bienes jurídicos individuales por sobre los bienes jurídicos colectivos.

No me parece que este argumento sea dirimente. En muchas ocasiones los derechos individuales (el derecho a trabajar o a ejercer la industria) ceden ante derechos colectivos (la no contaminación ambiental), por lo que la antinomia bien individual/bien colectivo es un dato indiciario, no dirimente, para resolver la jerarquía de dos derechos o deberes en pugna.

Insisto que, más allá de los intensos esfuerzos por demostrar que el delito de quiebra merece mas protección que el de cheque sin fondos, los argumentos desarrollados por Verde son meramente prima facie, pero no logran decantarse, de manera dirimente, a favor de uno u otro deber jurídico.

\section{José Milton Peralta.}

\subsection{La función de las escalas penales.}

En un meduloso análisis, Peralta critica, acertadamente, mi siguiente afirmación:

no puede afirmarse que 'no matar' es más importante que 'no dañar al patrimonio' porque el primero está penado más severamente que el segundo, sino lo contrario: porque la vida es más importante que el patrimonio es que 'no matar' tiene mayor pena que 'dañar al patrimonio.'

\footnotetext{
7 Salvo d'Almeida, los otros críticos (Ortiz de Urbina, Verde y Peralta) han criticado este párrafo. Si bien ya he esbozado algunas respuestas a Ortiz de Urbina y a Verde, me detendré un poco más en el análisis de Peralta ya que, a mi entender, ha sido el más agudo respecto de esta cuestión.
} 
Peralta sostiene que esa afirmación puede ser entendida tanto en forma descriptiva como en forma prescriptiva. Si se entiende como descripción de lo que el legislador hace no habría mayores inconvenientes en solucionar el conflicto, ya que sería evidente que el patrimonio común de los acreedores de una quiebra es más importante que la fe pública.

Según Peralta, si se entiende de manera prescriptiva mi posición (interpretación que Peralta favorece), no es fácil ver qué consecuencias acarrearía. Una posible consecuencia sería que las escalas penales son superfluas, ya que si reflejan la genuina importancia de los bienes jurídicos, entonces tendrían un mero carácter declarativo, y si no reflejan tal importancia entonces serían inválidas.

No estoy seguro de que las conclusiones a las que arriba Peralta sean consecuencias necesarias de mi aserción; pero si posee tales consecuencias, las rechazo. Mi intención era mucho más modesta: intentaba señalar que frente a escalas penales tan similares (de seis meses a cuatro años de prisión para el delito de cheque sin fondos, y de dos a seis años de prisión para el delito de quiebra fraudulenta) tal similitud nos impide determinar cuál es el bien jurídico que posee mayor importancia y, en definitiva, qué deber jurídico debe prevalecer.

También es atinada la crítica de Peralta respecto de mis aserciones referidas a que la modalidad de ataque al bien jurídico puede incrementar la escala penal, pero por ello no significa que el bien jurídico en sí tenga mayor valor que el bien jurídico en pugna. Si bien ello es aceptado por Peralta, el autor critica las consecuencias que yo extraigo de la misma: para Peralta las escalas penales combinan la importancia del bien jurídico tutelado con la modalidad de ataque, y en la ponderación de los deberes jurídicos en pugna no solo es importante el bien jurídico sino la concreta modalidad de ataque que el deber pretende proteger.

Sobre la base de estas críticas, que acepto parcialmente, Peralta concluye que dada la mayor protección penal del delito de quiebra (por estipular mayor escala penal), el deber jurídico que prevalece es el de no pagar el cheque. 
Sin embargo, estas concesiones parciales que efectúo a las críticas de Peralta, no impactan en mi conclusión final, respecto de que no puede determinarse cuál es el bien jurídico de mayor jerarquía. Y ello por dos razones.

La primera es reconocida parcialmente por Peralta, cuando coincide en mi análisis respecto del hecho que las escalas penales en juego tienen gran parte en común (el tramo que va de dos a cuatro años), agregando que no puede descartarse que en ciertos casos concretos la pena a imponer por cometer uno u otro delito se encuentra dentro de ese rango común. Lamentablemente Peralta no continúa su argumento, pero si eso fuera así, en ese caso los deberes jurídicos en juego tendrían exactamente la misma jerarquía, y la solución debería ser la propuesta en "Normas Penales y Conflicto de Deberes": haga lo que haga el agente, no puede ser sancionado penalmente.

La segunda razón ya fue esbozada al criticar a Ortiz de Urbina. El delito de quiebra reprime a quienes efectúan "pagos indebidos", por lo tanto, de manera previa a analizar las escalas penales, debería elucidarse si pagar el cheque rechazado es un "pago indebido". Sería un pago "indebido" según la ley de quiebra, pero no lo sería según la ley de cheque con refuerzo en el art. 302 inc. 1 del código penal. ¿Por qué no sostener que se trata de un pago "debido" en aras de proteger la fe pública y la transparencia y previsibilidad del mercado monetario en general y de los títulos circulatorios en particular?

Recordemos que el delito de cheque está en el mismo título que el delito de colocar moneda falsa en el mercado (protegen el mismo bien jurídico). ¿Consideraríamos prohibido que el fallido trueque moneda falsa por moneda genuina si alguna norma penal se lo exigiera bajo amenaza de pena?

Creo que las dudas son muchas y las mismas impiden afirmar de manera categórica que el deber jurídico de no pagar el cheque (por el delito de quiebra) es jerárquicamente superior al deber jurídico de pagarlo (por el delito de cheque). 


\subsection{La indominabilidad normativa.}

Sobre el tema de la indominabilidad normativa, Peralta, al igual que Verde, considera que sostengo que el conflicto de deberes es una causa de justificación supralegal. Nunca he dicho tal cosa. Para el caso por mí analizado, la única causa de justificación es el "cumplimiento de un deber" (art. 34 inc. 4 cód. penal). El tema es que una norma penal exige un deber (el de pagar) y la otra norma penal exige el deber inverso (no pagar). Como se trata de un conflicto de deberes me pareció atinado revisar la posición de Roxin, pero tal revisión no supone que yo he aceptado, como sí parece aceptar Roxin, que el conflicto de deberes es una causa de justificación extralegal. siguiente:

Peralta afirma que mi posición es paradójica, por lo

dada la situación $\mathrm{S}$ rige la norma $\mathrm{N} 1$ que deroga la norma $\mathrm{N} 2$ y al mismo tiempo dada la misma situación $\mathrm{S}$ rige la norma N2 que deroga la norma N1. Pero es inconcebible. Si N1 deroga a N2 entonces ya N2 no puede derogar N1, y viceversa. Dos normas no pueden derogarse simultáneamente mutuamente, porque para que una norma $\mathrm{N} 1$ derogue una norma $\mathrm{N} 2$ es necesario que tenga vigencia, es decir que la norma N2 no derogue al mismo tiempo, la norma N1.

Creo que Peralta queda atrapado en las palabras que ha elegido. Más que "derogar" (que parece tener como consecuencia la pérdida de la vigencia) la palabra correcta sería "derrotar" o "prevalecer", siguiendo el término "defeasibility" introducido por $\mathrm{Hart}^{8}$. Si N1 prevalece sobre N2 en un caso concreto, N2 no pierde vigencia; simplemente prevalece o "la derrota".

Aclarado este punto, lo paradójico es el sistema normativo del ciudadano, y no, como sugiere Peralta, la presentación que yo efectué del mismo. Es evidente que en algún sentido el deber de pagar

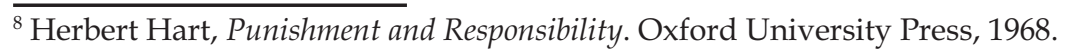


el cheque excepciona el delito de quiebra y, en otro sentido, el deber de no pagarlo excepciona el delito de cheque sin fondos. La cuestión, insisto, es si un deber prevalece sobre (o derrota a) el otro.

Luego Peralta sostiene que si es el caso que ambas normas se neutralizan mutuamente entonces es imposible determinar la conducta típica, "ya que si no se puede establecer qué norma prevalece no se puede determinar el tipo penal (ni el de prohibición ni el de obligación) en el sentido de la norma secundaria". Concluye Peralta que la conducta del sujeto será atípica por no estar regulada por el derecho en sentido fuerte.

Estoy de acuerdo en las conclusiones finales de Peralta, más no en el modo en que arriba a ellas. No me parece que se trate de una conducta atípica, como sostiene Peralta en su argumentación; es más, de sostener la atipicidad me parece más sustentable la posición de Zaffaroni de atipicidad conglobante. Pero rechazo la atipicidad. Como señalé en "Normas Penales y Conflicto de Deberes" me parece que el camino es la ausencia de antijuridicidad por la ausencia de un "accionar conforme a derecho" posible.

Creo que el error de Peralta es presuponer (como presuponen muchos dogmáticos) que no existen sistemas inconsistentes; o que, más allá de ciertas inconsistencias de la ley, la dogmática penal posee herramientas superpoderosas para tornar consistente lo que no lo es.

Los analíticos somos más modestos en cuanto a las potencialidades de los sistemas normativos y los sistemas dogmáticos. Ambos están hechos por seres humanos y pueden poseer errores.

Creo que, justamente, estamos frente a un error legislativo en donde dos normas ser derrotan mutua y simultáneamente. Se trata de dos normas secundarias que permiten normas opuestas, que derrotan tipos penales inversos. Por tanto, ambas conductas están permitidas, la de pagar el cheque y la de no pagarlo.

\subsection{Actio illicita in causa.}

Peralta explora una alternativa no analizada en "Normas Penales y Conflicto de Deberes"; aquella situación según la cual el sujeto 
libra el cheque a sabiendas de que será declarado en quiebra (por ej., porque ya entró en cesación de pagos). En tal situación, el sujeto puede ser sancionado cualquiera sea la acción que realice: si paga el cheque será sancionado; si no lo paga, también.

El fundamento de tal necesaria punición se encuentra, según Peralta, en la exigencia de que el sujeto sea "extraño" a la situación de necesidad, entendiéndose que un sujeto es "extraño" a la situación de necesidad cuando la misma no le puede ser imputada; por ej. cuando la situación se generó por caso fortuito o es imputable a un tercero.

Trasladado al caso en estudio, Peralta indica que la norma en cuestión, sancionadora de la actio illicita in causa, señalaría "está prohibido emprender un conducta que implique el riesgo de colocarse ante dos situaciones incompatibles e igualmente típicas". Según Peralta, estaría prohibido librar el cheque si existe el riesgo de que al deber pagarlo se tenga que realizar un ilícito penal.

La clave, entonces, es determinar si al momento de librar el cheque el librador conocía que existía certeza de que se decrete su quiebra. La mera posibilidad de una quiebra futura no segura, creo, descarta la tesis de Peralta.

Sin embargo Peralta termina descartando esta hipótesis porque la actio illicita in causa sólo está prevista para el estado de necesidad (art. 34 inc. 3 cód. penal) y no para el cumplimiento de un deber (art. 34 inc. 4 cód. penal). Aplicar este instituto significaría una analogía en contra del imputado. Coincido con Peralta en que, sobre esta cuestión, nos enfrentamos ante una laguna axiológica.

\section{Palabras Finales.}

Más allá de los esfuerzos de los cuatro críticos, entiendo que mis tesis centrales sostenidas en "Normas Penales y Conflicto de Deberes" no han sido rebatidas. Reconozco que han introducido observaciones a ciertos párrafos o formulaciones de mi trabajo que merecen ser atendidas, pero en nada han subvertido las tesis centrales. Hacia ellos mi agradecimiento por haber dedicado su tiempo a leer mi trabajo y criticarlo agudamente. 
Por último agradezco a dos amigos. A Pablo Navarro, director de Discusiones, por haber elegido un trabajo mío para ser parte de su colección. A Hernán Bouvier por haber coordinado el número con infinita paciencia a mi persona. 